\title{
INTRODUCTORY OVERVIEW
}

\section{Advancing sexual and reproductive health and rights in low- and middle-income countries: Implications for the post-2015 global development agenda}

\author{
Adrienne Germain ${ }^{\mathrm{a}}$, Gita Sen $^{\mathrm{b}}$, Claudia Garcia-Moreno ${ }^{\mathrm{c}}$ and Mridula Shankar ${ }^{\mathrm{d} *}$ \\ ${ }^{a}$ President Emerita, International Women's Health Coalition, New York, NY, USA; \\ ${ }^{b}$ Ramalingaswami Centre on Equity and Social Determinants of Health, Public Health Foundation \\ of India, Bangalore, India; ${ }^{c}$ Department of Reproductive Health and Research, World Health \\ Organization, Geneva, Switzerland; ${ }^{d}$ The Judith Lumley Centre, La Trobe University, Melbourne, \\ VIC, Australia
}

(Received 19 October 2014; accepted 6 November 2014)

\begin{abstract}
The papers and commentaries in this special issue illuminate progress made by lowand middle-income countries towards implementation of the Programme of Action (PoA) agreed by 179 countries during the International Conference on Population and Development in Cairo in 1994. The PoA presents a path-breaking sexual and reproductive health and rights (SRHR) framework for global and national population and health policies. While progress towards implementation has been made at global, regional and national levels, continuing and new challenges require that high priority be given to SRHR for all, particularly women and girls, during the remaining months of the millennium development goals and in the United Nations post-2015 development agenda. This paper highlights three critical gaps, raised in other papers: inequalities in access to sexual and reproductive health (SRH) information and services; the widespread need to improve SRH services to meet public health, human rights and medical ethics standards for quality of care; and the absence or inadequate use of accountability mechanisms to track and remedy the other two. We discuss priority actions to achieve equality, quality and accountability in SRHR policies, programmes and services, especially those that should be included in the post-2015 development agenda.
\end{abstract}

Keywords: sexual and reproductive health and rights; low- and middle-income countries; post-2015 global development agenda; equality of access to SRH services; quality of SRH services; monitoring and tracking of SRH services

\section{Background}

This special issue was conceived to reflect on progress towards sexual and reproductive health and rights (SRHR) in low- and middle-income countries (LMICs), since the historic paradigm shift in population policy made by the 1994 United Nations International Conference on Population and Development (ICPD) and reinforced at the Fourth World Conference on Women (FWCW) in Beijing in 1995. It is published just as governments are negotiating at the United Nations on actions to accelerate progress towards sustainable human development through the United Nations post-2015 global development agenda. The issue reviews and reflects on available evidence, and

*Corresponding author. Email: m.shankar@latrobe.edu.au 
recommends priority actions to achieve SRHR, particularly of women and adolescents, in LMICs.

Among the many worldwide mobilising efforts for the ICPD over 20 years ago, two in particular can be seen to underpin this set of papers: the political statement made by an unprecedented meeting of 215 women from 79 different countries in Rio de Janeiro in January 1994, 'Reproductive health and justice: International women's health conference for Cairo 1994' (The Rio Statement of Reproductive Health and Justice, 1994); and the March 1994 book of essays, 'Population policies reconsidered: Health, empowerment, and rights' (Sen, Germain, \& Chen, 1994). Both sought a pivotal change in population policies, from fertility control as the primary aim, to policies for sexual and reproductive health (SRH), empowerment and human rights, including sexual and reproductive rights, not only for couples, but also for individuals, particularly women and adolescents. Almost all of the proposals in the two publications were agreed in the ICPD Programme of Action (PoA) (United Nations, 1995a), which has been reaffirmed and further elaborated many times since 1994, including annually by governments at the United Nations.

The ICPD PoA defined reproductive health to include sexual health (United Nations, 1995a, para 7.2), and identified a core set of services, commonly summarised to include contraception, safe abortion, maternity care, and prevention and treatment of sexually transmitted infections (STIs) and HIV (United Nations, 1995a, para 7.6). The World Health Organisation (WHO) recognises these SRH services as a 'guaranteed minimum' (World Health Organization, 2011a), and we use the term 'core SRH services' to refer to these. Reproductive rights are explicitly defined by the PoA (United Nations, 1995a, para 7.3) as the right of all couples and individuals to determine the number and timing of their children, and to have access to the means to do so, including reproductive health services, free of discrimination, coercion and violence.

While the PoA did not explicitly define sexual rights, it includes many paragraphs that protect the right to access SRH services and information regardless of age or marital status, essential for everyone, including adolescents, to realise their human rights in relation to their sexuality. It also addresses the challenges of child marriage, endemic violence against women and girls, and other abuses of human rights and fundamental freedoms in relation to sexuality (Kismödi, Cottingham, Gruskin, \& Miller, 2014).

The FWCW reaffirmed these commitments and further elaborated on them, saying 'The human rights of women include their right to have control over and decide freely and responsibly on matters related to their sexuality including sexual and reproductive health, free of coercion, discrimination and violence' (United Nations, 1995b, para 96). Since the ICPD and FWCW, it has become common to refer to this group of rights and services as 'SRHR', though the term as such has not yet been accepted in a global intergovernmental agreement (Kismödi et al., 2014). The explicit recognition of SRHR in the ICPD and FWCW deepened and further broadened the understanding of the right to health, going beyond the right to health services alone, by focusing on girls' and women's rights to bodily autonomy, integrity and choice in matters of sexuality and reproduction (Sen, 2014).

On September 11-12, 2014, the United Nations General Assembly debated the basic content of a Post-2015 Global Development Agenda (P15 Agenda) proposal developed by the 'Open Working Group' (OWG) of member states over the previous 12 months. In the ongoing process of defining the P15 Agenda, 2 of the 17 proposed goals are directly relevant to SRHR: Goal 3 on health, and goal 5 on gender equality. The inclusion of these two goals in the OWG proposal was hard won, in spite of support from multiple stakeholders, including governments, experts and activists. Moving forward, as 
negotiations continue to elaborate and finalise the P15 Agenda, proponents aim to position SRHR as a central element of the development and human rights framework, and to address the critical gaps identified in this paper and the issue overall.

\section{Where are SRHR 20 years after ICPD?}

While a paradigmatic change such as that made by the ICPD takes time to come to full fruition, the papers in this issue illustrate meaningful advances, despite challenges posed by many contextual factors. First, important progress has been made towards improved SRH outcomes (Snow, Laski, \& Mutumba, 2015) and policies for SRH service provision, although much remains to be done (Ahonsi, 2014; Diniz \& Araújo, 2014; Jahan \& Afsana, 2014; Vaidyanathan, 2014). Second, while countries and regions have witnessed both forward movement and continuing challenges in advancing sexual and reproductive rights (Luczon \& Francisco, 2015; Ilkkaracan, 2015), the overall direction is significantly positive (Kismödi et al., 2014; Snow et al., 2015). Third, the populations of most LMICs are young (though population ageing is also beginning). These large cohorts of adolescents, aged 10-19, are demanding their SRHR, including education and services appropriate to their needs (Santhya \& Jejeebhoy, 2015). Fourth, while the last two decades have seen a patchwork of health sector reforms that have had mixed and often unsatisfactory effects on equality of access and on the quality of SRH services, significant national efforts demonstrate the possibility of alternative approaches that promote both equality and quality (Fang, 2014; Ibáñez \& Garita, 2015; Tangcharoensathien, Chaturachinda, \& Im-Em, 2014). These experiences provide valuable lessons for approaches to universal health care and coverage (UHC) and other reforms that can advance SRHR (Sen \& Govender, 2014).

The findings of the United Nations 'operational review' of progress on implementing the ICPD PoA (United Nations General Assembly, 2014), and this issue, confirm what the population, health and development fields are increasingly acknowledging, namely, that despite significant progress on some aspects of SRHR for some people in LMICs, three major gaps (Sen, 2014) require priority attention:

- Inequalities in access to SRH services, education and information have left women and adolescents in the lowest two wealth quintiles, living in rural and other hard-to-reach areas, far behind (Santhya \& Jejeebhoy, 2015; Snow et al., 2015).

- The quality of SRH services falls far short of human rights and public health standards, and, often, medical ethics standards as well (Kismödi et al., 2014; Sen \& Govender, 2014).

- Accountability mechanisms do not exist or are not used to track progress, or to prevent and redress inequalities and poor quality of services in most countries (Kismödi et al., 2014).

These three gaps reflect fundamental failures by governments and their development partners to understand and act in accordance with the human rights foundation of the ICPD PoA. Successfully integrating SRHR into the post-2015 development agenda requires attention to remedying these gaps and re-positioning SRHR within a framework of human rights as articulated in the PoA. Two papers in this issue elaborate action priorities in the realms of health policies and legislation. 
First, with support for UHC as the key driver for health systems reform in the post2015 era gaining momentum, Sen and Govender (2014) argue that attention to the gaps in SRHR and, in particular, to equality, quality and accountability, intrinsic to the SRHR agenda, will lead to a more equitable path (via attention to the needs of the most marginalised) to achieve UHC. Commentaries from Mexico (Ibáñez \& Garita, 2015), Thailand (Tangcharoensathien et al., 2014) and China (Fang, 2014) provide illustrative examples of policy and programming approaches for prioritising SRHR within a broader set of healthcare reforms, and review national progress and challenges for the realisation of SRHR.

Second, Kismödi et al. (2014) bring attention to the central importance of human rights standards in advancing SRHR through legislation, including the principles of nondiscrimination and accountability to combat inequality and ill-health, particularly focusing on sexual health. Their analysis emphasises the importance of continued investments to remove legal and regulatory barriers to SRHR. Commentaries from the Philippines (Luczon \& Francisco, 2015), the Middle East and North Africa regions (Ilkkaracan, 2015) highlight the fundamental roles played by civil society advocates and social movements in demanding legislative, social and policy reforms for advancing sexual and reproductive rights in line with human rights principles.

This paper further elaborates on how a focus on three pivotal elements of human rights-based SRH services, namely equality of access, quality of services, and greater accountability through better information and monitoring of both, can fulfil the ICPD vision of SRHR from now until the 2015 end of the millennium development goals (MDGs), and in the post-2015 global development agenda.

\section{Moving forward into the post-2015 global development agenda}

The ICPD paradigm shift to SRHR reflects global commitment to the fulfilment of international human rights, particularly the right to health, and the human rights of women and adolescents, especially girls, as necessary building blocks of development. The right to health, i.e., 'the right of everyone to the enjoyment of the highest attainable standard of physical and mental health', requires, inter alia, that quality services be available and accessible (including affordable) and acceptable to all (United Nations Committee on Economic, Social and Cultural Rights [CESCR], 2000). These requirements are commonly identified by the acronym AAAQ; and governments must be held accountable for meeting these standards (Kismödi et al., 2014; Santhya \& Jejeebhoy, 2015; Sen \& Govender, 2014; Snow et al., 2015). While many countries cannot immediately meet these standards because of shortage of resources and personnel, for instance, every country is obligated to have explicit policies and work plans for their eventual achievement, that is, for 'progressive realisation' of the right to health.

Actions needed to meet these standards are identified below. The first, equality of access, considers how the health sector can improve service availability and accessibility, while recognising that actions by other sectors are also essential. The second section delineates actions required to achieve quality of services that meets human rights, public health and medical standards. The third addresses means to ensure accountability for shortfalls and to promote progress in protection of sexual and reproductive rights, including delivery of SRH services and information. 


\section{Achieving equality of access}

Snow et al. (2015) provide evidence to demonstrate the stark inequalities in access to a range of SRH services across regions, between wealthy and economically disadvantaged women and for women living in rural areas. Commentaries on Nigeria (Ahonsi, 2014), Bangladesh (Jahan \& Afsana, 2014), Brazil (Diniz \& Araújo, 2014) and the Tamil Nadu state in India (Vaidyanathan, 2014) make the case that significant progress can be made by the health sector in LMICs. As indicated in the Commentary by Garcia-Moreno and Temmerman (2015), multi-sectoral approaches are feasible and can overcome some of the most pervasive of challenges affecting the health and rights of women and girls. Accelerated progress towards equality requires health policies, planning and financing to focus explicitly and concurrently on increasing service availability and improving access for the most disadvantaged groups, namely women and adolescents, particularly girls, in the lower wealth quintiles and living in hard-to-reach areas. Deliberate and specific adjustments need to be made in the planning, budgeting and implementation of health services to remove geographic barriers by, for example, developing healthcare infrastructure and increasing the distribution of trained health workers in remote areas, streamlining the supply chain of healthcare commodities, and setting up effective referral pathways to support a continuum of care. Facilitating voluntary choice is essential to accessibility and requires health systems to provide pervasive information on where, when and the types of services available, for whom and at what cost, and the means by which such information can be easily accessed. Equally, accessibility depends on the quality of care offered, addressed in the next section.

Importantly, equality of access requires concerted actions across multiple sectors to reduce the social, legal and economic barriers that women and adolescents, especially girls, face in accessing services. As Santhya and Jejeebhoy (2015) demonstrate, a large proportion of adolescent girls marry before age 18 and lack the agency, information and skills to remain healthy. Addressing these and other barriers require, inter alia, expanding access to comprehensive sexuality education for all adolescents ages 10-19 (Germain, 2014), creating safe space programmes for vulnerable girls, investing in the education of the poorest girls and women, and the removal of legal and other restrictions in access to contraception and to safe abortion, particularly for adolescents. The Commentary by Bruce (2015) argues that early investments in the poorest girls from the poorest communities can have important pay-offs in terms of their health and empowerment.

\section{Improving service quality}

Four recent reviews of progress towards operationalising and implementing the main elements of good-quality care, including in countries with weak health systems and limited resources (Askew \& Brady, 2013; Hardee et al., 2013; United Nations General Assembly, 2014; WHO, 2011b), assess available literature and contain bibliographies that together constitute a comprehensive inventory (at least in English) of what has been done to improve quality of care, primarily in family-planning services. Available evidence suggests that achieving quality standards improves the effectiveness of SRH information and services, encourages people to use them effectively, and attracts new people to use them (Darroch \& Singh, 2013). The reverse is also true - poor quality discourages use (Jain, Ramarao, Kim, \& Costello, 2012; Askew \& Brady, 2013). To date, despite such evidence and the fact that improvements can be made even in countries with limited capacity and resources, very little attention has been given to quality of care as defined here. 
Accelerating progress towards provision of quality SRH information, services, and rights protections, especially for disadvantaged women and girls of all ages whether married or not, in ways suited to each person's changing circumstances and health conditions, requires focused and deliberate planning, financing, implementation, monitoring and evaluation, appropriate to the circumstances of each country and sub-national region. These processes and many particular improvements need not be costly or cumbersome. What is needed is interest and commitment of the main actors, especially governments and their development partners.

We delineate next the priority actions to close the quality gap in SRH services and information, namely integration of SRH services with each other, a major gap in most countries, reorientation of the training and supervision of services providers, and enabling informed choice.

\section{Integration of $\mathrm{SRH}$ services}

Human rights standards, medical ethics and clinical standards encourage integration of the core SRH services (listed above) with each other. Integration remains a central demand of women's health advocates and professionals, in order to meet women's multiple, concurrent and synergistic SRH needs and to provide sustained and systematic care over time (UN Women in collaboration with ECLAC, 2013). Integrated services save time and other costs for women, and also yield efficiencies for health systems.

Nonetheless, it appears that most SRH services in LMICs are delivered vertically or combine at most two SRH services, and then only for particular groups, such as women living with HIV and AIDS. The global review of implementation of the ICPD PoA could not assess progress towards integration because neither countries nor the global community have collected these data (Snow et al., 2015).

At a minimum, progress towards integrated services, which address each person's needs at particular points in time and also across the life course, requires health systems to:

- assess and eliminate legal, administrative, policy and other barriers to integrate SRH services, with priority to the removal of barriers that affect the most vulnerable and disadvantaged groups, such as lack of facilities, stock outs, absence of necessary personnel, and laws or regulations that restrict access to certain services (e.g., safe abortion) or by certain groups (e.g., adolescents, single women), among others;

- develop plans and specific actions to train healthcare providers to cover at least the four core SRH services, and to effectively refer clients for services, which they, or their facility, cannot yet provide;

- experiment with provision of multiple services in selected sites in order to learn how best to proceed with integration of SRH services across the system; and

- develop and use specific indicators to assess progress towards integration of services as a required element of monitoring and accountability.

\section{Reorientation of training and supervision of service providers and managers and enabling informed choice}

Concomitant with the planning and actions to progressively integrate SRH services with each other, health systems and programmes must: 
- Design and implement protocols for training, service delivery and supervision to ensure that clinical, ethical and human rights standards are met, especially as SRH services are expanded geographically and demand for services increases (Sen \& Govender, 2014).

- Ensure the widest possible range of choices among methods for each of the four core SRH services (e.g., vacuum aspiration and medical technologies for abortion; both male and female condoms for STD and HIV prevention; and the like).

- Tailor all forms of communication, from public education and outreach through one-on-one counselling, so that they respect and facilitate the client's right to decide.

\section{Quality improvement illustration: contraceptive services}

The priority actions suggested below for contraceptive services illustrate the kinds of adjustments that must be made in each SRH service to improve quality of care. (For analogous suggestions on other SRH services, see, for example, UNFPA's report of the expert consultation meeting 'Women's health - rights, empowerment and social determinants' in Mexico City, 2013) (United Nations Population Fund [UNFPA], 2014). We focus on contraceptive services for several reasons. Resurgent interest in, and funding for, contraceptive services (e.g., the FP2020 initiative, http://www. familyplanning2020.org/) provides a major opportunity to institutionalise practices and deliver information and services that meet public health and human rights standards, as well as medical ethics standards. Further, family-planning services are commonly the first or only SRH service available to disadvantaged women in countries with weak health systems and limited resources. Moreover, significant abuses of human rights and severe shortfalls in other aspects of the quality of contraceptive services still occur and must be addressed in many countries. Three priority actions are outlined below.

First, the increasingly diverse clientele of family-planning services requires a wider range of contraceptive methods than the minimum standard of three currently used by governments and other key actors. Planning, procurement and delivery of contraceptive commodities, with priority to areas where large concentrations of disadvantaged women and adolescents live, should rather include a minimum of five types of methods that work in different ways and are differently suited to diverse life circumstances: male and female condoms; one short- and one longer-acting hormonal method (e.g., one oral pill type, plus an injectable or an implant); emergency contraception; one long-acting, non-hormonal method (IUD); and, where health system capacity allows or can be developed, both male and female sterilisation. Further, service providers must not be incentivised, directly or indirectly, to 'motivate' or 'persuade' clients to use a particular type of method, as is currently the case in many countries. Rather, providers must be held accountable for enabling clients to make informed and free choices based on provision of full and accurate information about side effects, and risks and benefits of each method (WHO, 2014).

Both procurement of contraceptive commodities and health worker training must support women who want to switch methods. Twenty years ago and today, research shows that as many as $35-40 \%$ of contraceptive users discontinue use of their method within 6-12 months for reasons related to the quality of services (Cleland \& Shah, 2013; Curtis, Evens \& Sambisa, 2011) and either do not know about, or are not supported by, service providers to choose an alternative method. Of particular importance is ensuring that SRH service providers have both skills and instructions to give higher priority to 
condoms, especially for adolescents and youth and in contexts where prevalence of STIs and/or HIV is high, and to remove contraceptive implants and IUDs on request.

Second, healthcare providers must be trained and supported not only to meet medical and ethical standards, but, with much greater emphasis, to respect the human rights of the persons they serve, particularly non-discrimination (especially for adolescents, youth and unmarried persons), privacy, confidentiality and choice with special support to those who may not be experienced decision makers, such as young married women and adolescent girls. They must provide full information on the possible importance of contraceptive side-effects for each individual, and must assist girls and women to weigh their risk of STIs and HIV when deciding what contraceptives to use.

Third, all types of information on contraception must be delivered without bias. In contrast, current programmes, such as FP2020, which aim to reduce the 'unmet need for family planning', defined as women who want to avoid pregnancy but are not using modern methods of contraception, all too often emphasise promotional content. A typical example of such emphasis is in a December 2012 Population Council Policy Brief, 'Designing and Implementing High-Quality Voluntary Family Planning Programs', which lists the following as one of seven 'best practices': 'Family planning programs must build in a robust communications component to convey the benefits of contraception and motivate people to adopt family planning when they would like to avoid pregnancy' (Population Council, 2012) (authors' emphasis, not the Council's).

Information, public education and communications, as well as outreach workers' training and assignments, must instead be designed to support free and informed decisions about contraception by indicating the methods available and the pros and cons of different methods including side-effects and risks, where they can be obtained, when, and with what requirements, such as fees. While universal access for all women, men and adolescents is the ultimate goal, reaching adolescent girls, especially those $10-14$, and the younger end of the 15-19-year range, who are at high risk of human rights abuses and poor SRH outcomes, requires urgent and specific planning, training of staff, and investments in outreach and comprehensive sexuality education programmes as noted in the section above on equality (Germain, 2014; Santhya \& Jejeebhoy, 2015).

\section{Planning for and tracking progress towards equality and quality}

Accountability systems, including formal grievance and redress mechanisms, as well as community participation in monitoring SRH services, are essential to achieving equality, quality and accountability in SRHR, an ICPD principle. Nonetheless, these have so far been honoured primarily in the breach. There is an urgent need to take a fresh look, from this perspective, at the range of measures used to monitor SRHR services, education and information (Fukuda-Parr, Yamin \& Greenstein, 2014; Sen \& Mukherjee, 2014; Yamin \& Boulanger, 2014).

For instance, commonly used planning tools and outcome measures for contraceptive services, required by donors as well as governments, have been in use since national population and family-planning programmes began in the 1970s, when circumstances were very different. Fulfilling the health and human rights of women and adolescent girls now requires, among other actions, modification of today's main planning tool, 'unmet need', to encompass not only women and girls who are not using contraception, but also women and girls who are using contraceptives but are dissatisfied with or unable to use their current method effectively (Dixon-Mueller \& Germain, 1992). It further requires accurate records that follow the client as she uses various SRH services over time. 
Revised and new programme monitoring measures, which track the quality, not only the quantity, of SRH services, and inequalities in access to services are urgent.

An example of this challenge is a common measure of family-planning 'success' 'couple years of protection' (CYP), used currently by FP2020 and Countdown 2014, among others. Like many conventional family-planning measures, CYP tracks contraceptives, not the people using them. Used alone, CYP and other quantitative measures to assess the 'success' of initiatives such as FP 2020 tell us nothing about the SRHR of the individuals receiving services, and can also bias the range of services provided. For instance, using CYP promotes a bias towards longer-acting contraceptive methods and sterilisation, which have high intrinsic CYPs, are not subject to 'user failure' and require less resupply. In practice, the result is inadequate choices, especially for women in rural and other hard-to-reach places. Measures such as CYP can thus unintentionally subvert human rights standards, which require that all clients have an unbiased choice among a wide range of contraceptives appropriate to their specific needs (Jain \& Bruce, 1994).

Another example is tracking comprehensive sexuality education, which has so far emphasised evaluations of its impact on 'behaviour change' (Santhya \& Jejeebhoy, 2015). Such assessment is not only technically challenging and very costly, but also provides little indication of the quality of programmes or their reach. Given that few countries have such programmes, especially at national scale, it would be more useful instead to assess the extent to which national curricula and teaching use the UNESCO guidance (United Nations Economic, Social and Cultural Organization [UNESCO], 2009); to estimate the proportions of adolescents, aged 10-14 and 15-19, who have access; and to monitor the quality of content and delivery once national standards are set.

Similarly, using the maternal mortality ratio (MMR) as the main outcome measure for a maternal health goal tends to conflate the multiple factors (changing demographic profile of the population, improved maternal health services, effective use of contraception, or access to safe abortion, to name only some) that underpin it. It has therefore been something of a blunt instrument at best (Yamin \& Boulanger, 2014) or even distortionary (Jain, 2011). It would be more useful if key measures of the different factors contributing to maternal health, such as effective use of contraception or access to safe abortion, were to be used along with the MMR. More generally, greater emphasis needs to be placed on measuring equality as a critical component of progress. Tracking equality in access to SRH services across age (especially for the often excluded category of adolescents aged 10-14), economic status, geographical location and caste/racial/ethnic categories, to name a few, is essential in monitoring the status of existing inequalities in the provision of and access to SRH information and services, and guiding actions to reduce them.

\section{Conclusion}

The papers in this issue argue that continuing implementation of the ICPD, completion of the MDGs and the post-2015 global agenda must prioritise equality, quality and accountability in SRHR through actions to:

- formulate and implement health system reform policies that advance SRHR by ensuring that financing, services, supplies, human resources training and deployment, management, regulation and monitoring of SRH services achieve the key elements of the right to health, i.e., availability, accessibility (including affordability), acceptability and quality (UNESCO, 2000; WHO, 2005); 
- reduce inequalities by making information and integrated SRH services available and accessible to all, but especially to women who are disadvantaged and/or discriminated against, and to all adolescents especially girls;

- address key determinants of women's and adolescents' SRHR, including through, multi-sector commitments to eliminate violence against women and to support survivors (Garcia-Moreno \& Temmerman, 2015), and to end harmful practices such as early and forced marriage (Santhya \& Jejeebhoy, 2015) and female genital mutilation;

- protect the human rights of all to privacy and confidentiality, and to fully informed and free choice, in SRH services; to comprehensive sexuality education, and other SRHR information and education, which informs and enables but does not 'persuade' or 'motivate'; and to mechanisms for redress of human rights abuses as part of comprehensive systems of accountability for SRHR; and

- develop and strengthen indicators and tracking mechanisms that build health system accountability for reduction of inequalities and improved quality of SRH services.

Intergovernmental agreements following the ICPD, beginning with the 1995 Fourth World Conference on Women, have repeatedly urged governments to act on these areas. A multitude of research and, commonly small-scale, experiences exist that demonstrate the feasibility of most of the actions suggested above. This special issue makes clear that such actions can produce results in countries with quite diverse epidemiological profiles and health systems capacity. Nonetheless, for primarily political reasons, the proposals to date for the post-2015 global agenda goals and targets fall short of the comprehensive inclusion of SRHR. As negotiations continue, consensus on the inclusion of SRHR, with emphasis on equality, quality and accountability, at the core of a post-2015 sustainable development framework, can contribute to the development of meaningful targets and a transformative vision for human development that is rooted in human rights and health for all.

\section{Acknowledgement}

This work was carried out with the aid of a grant from Canada's International Development Research Centre.

\section{Disclaimer statement}

Claudia Garcia-Moreno is a staff member of the World Health Organization. The author alone is responsible for the views expressed in this publication and they do not necessarily represent the decisions or policies of the World Health Organization.

\section{References}

Ahonsi, B. (2014). Accelerating the quest for integrated and comprehensive sexual and reproductive health services in Nigeria. Global Public Health, 10(2), 174-176. doi:10.1080/17441692.2014. 986162

Askew, I., \& Brady, M. (2013). Reviewing the evidence and identifying gaps in family planning research: The unfinished agenda to meet FP2020 goals. Background document for the Family Planning Research Donor Meeting, Washington, DC, December 3-4, 2012, Population Council, New York, NY.

Bruce, J. (2015). Investing in the poorest girls in the poorest communities early enough to make a difference. Global Public Health, 10(2), 225-227. doi:10.1080/17441692.2014.986170

Cleland, J., \& Shah, I. H. (2013). The contraceptive revolution: Focused efforts are still needed. The Lancet, 381, 1604-1606. doi:10.1016/S0140-6736(13)60588-7 
Curtis, S., Evens, E., \& Sambisa, W. (2011). Contraceptive discontinuation and unintended pregnancy: An imperfect relationship. International Perspectives on Sexual and Reproductive Health, 37(2), 58-66. doi:10.1363/3705811

Darroch, J. E., \& Singh, S. (2013). Trends in contraceptive need and use in developing countries in 2003, 2008, and 2012: An analysis of national surveys. The Lancet, 381, 1756-1762. doi:10.1016/S0140-6736(13)60597-8

Diniz, S. G., \& Araújo, M. J. (2014). Reproductive health and rights in Brazil 20 years post ICPD. Global Public Health, 10(2), 183-185. doi:10.1080/17441692.2014.986167

Dixon-Mueller, R., \& Germain, A. (1992). Stalking the elusive "unmet need" for family planning. Studies in Family Planning, 23, 330-335. doi:10.2307/1966531

Fang, J. (2014). China's changing health system: Implications for sexual and reproductive health. Global Public Health, 10(2), 249-251. doi:10.1080/17441692.2014.986171

Fukuda-Parr, S., Yamin, A. E., \& Greenstein, J. (2014). The power of numbers: A critical review of millennium development goal targets for human development and human rights. Journal of Human Development and Capabilities, 15(2-3), 105-117. doi:10.1080/19452829.2013.864622

Garcia-Moreno, C., \& Temmerman, M. (2015). Actions to end violence against women: A multisector approach. Global Public Health, 10(2), 186-188. doi:10.1080/17441692.2014.986163

Germain, A. (2014). Promoting healthy adolescent development through comprehensive sexuality education. Global Public Health, 10(2), 222-224. doi:10.1080/17441692.2014.986176

Hardee, K., Newman, K., Bakamjian, L., Kumar, J., Harris, S., Rodríguez, M., \& Willson, K. (2013). Voluntary family planning programs that respect, protect and fulfill human rights: A conceptual framework. Washington, DC: Futures Group.

Ibáñez, X. A., \& Garita, A. (2015). Mexico: Moving from universal health coverage toward health care for all. Global Public Health, 10(2), 243-245. doi:10.1080/17441692.2014.986168

Ilkkaracan, P. (2015). Sexual health and human rights in the Middle East: Progress and backlash. Global Public Health, 10(2), 268-270. doi:10.1080/17441692.2014.986173

Jahan, R., \& Afsana, K. (2014). Sustaining progress toward comprehensive reproductive health services in Bangladesh. Global Public Health, 10(2), 180-182. doi:10.1080/17441692.2014.986164

Jain, A. K. (2011). Measuring the effect of fertility decline on the maternal mortality ratio. Studies in Family Planning, 42, 247-260. doi:10.1111/j.1728-4465.2011.00288.x

Jain, A., \& Bruce, J. (1994). A reproductive health approach to the objectives and assessment of family planning programs. In: G. Sen, A. Germain, \& L. Chen (Eds.), Population policies reconsidered: Health, empowerment, and rights (pp. 193-210). Boston, MA: Harvard University Press.

Jain, A. K., Ramarao, S., Kim, J., \& Costello, M. (2012). Evaluation of an intervention to improve quality of care in family planning programme in the Philippines. Journal of Biosocial Science, 44(1), 27-41. doi:10.1017/S0021932011000460

Kismödi, E., Cottingham, J., Gruskin, S., \& Miller, A. (2014). Advancing sexual health through human rights: The role of the law. Global Public Health, 10(2), 252-267. doi:10.1080/17441692. 2014.986175

Luczon, C. A. P., \& Francisco, G. S. (2015). Sustained advocacy produces success in the Philippines. Global Public Health, 10(2), 271-272. doi:10.1080/17441692.2014.986174

Population Council. (2012). Designing and implementing high-quality voluntary family planning programs. [Policy Brief]. New York, NY: Author.

The Rio Statement of Reproductive Health and Justice. (1994, January 24-28). International Women's Health Conference for Cairo. Rio De Janeiro. Retrieved from http://www.users. interport.net/i/w/iwhc/rio.html

Santhya, K. G., \& Jejeebhoy, S. J. (2015). Sexual and reproductive health and rights of adolescent girls: Evidence from low and middle-income countries. Global Public Health, 10(2), 189-221. doi:10.1080/17441692.2014.986169

Sen, G. (2014). Sexual and reproductive health and rights in the post-2015 development agenda. Global Public Health, 9, 599-606. doi:10.1080/17441692.2014.917197

Sen, G., Germain, A., \& Chen, L. (Eds.). (1994). Population policies reconsidered: Health, empowerment, and rights. Boston, MA: Harvard University Press.

Sen, G., \& Govender, V. (2014). Sexual and reproductive health and rights in changing health systems. Global Public Health, 10(2), 228-242. doi:10.1080/17441692.2014.986161

Sen, G., \& Mukherjee, A. (2014). No empowerment without rights, No rights without politics: Gender-equality, MDGs and the post-2015 development agenda. Journal of Human Development and Capabilities, 15, 188-202. doi:10.1080/19452829.2014.884057 
Snow, R., Laski, L., \& Mutumba, M. (2015). Sexual and reproductive health: Progress and outstanding needs. Global Public Health, 10(2), 149-173. doi:10.1080/17441692.2014.986178

Tangcharoensathien, V., Chaturachinda, K., \& Im-Em, W. (2014). Thailand: Sexual and reproductive health before and after universal health coverage in 2002. Global Public Health, 10(2), 246248. doi:10.1080/17441692.2014.986166

United Nations. (1995a). Report of the international conference on population and development. Programme of Action adopted at the International Conference on Population and Development, Cairo. (1994, September 5-13). (UN Doc. Cairo A/Conf. 171/13). New York, NY: Author. Retrieved from https://www.unfpa.org/webdav/site/global/shared/documents/publications/2004/ icpd_eng.pdf

United Nations. (1995b). Platform for action of the fourth world conference on women, Beijing, 1995. New York, NY: Author.

United Nations Committee on Economic, Social and Cultural Rights (UNCESCR). (2000). General comment no. 14: The right to the highest attainable standard of health. (E/C.12/2000/4). Geneva: United Nations.

United Nations Economic, Social and Cultural Organization (UNESCO). (2009). International technical guidance on sexuality education: An evidence-informed approach for schools, teachers and health educators (Vols. I and II). Paris: Author.

United Nations General Assembly. (2014). Framework of actions for the follow-up to the Programme of Action of the International Conference on Population and Development beyond 2014. Report of the Secretary-General. New York, NY: Author. Retrieved from http://www. unfpa.org/webdav/site/global/shared/documents/ICPD/Frameworkofactionforthefollow-uptothe PoAoftheICPD.pdf

United Nations Population Fund (UNFPA). (2014). Women's health - Rights, empowerment and social determinants. Report of the expert consultation meeting in Mexico City, September 30October 2, 2013, Author, New York, NY.

UN Women in collaboration with ECLAC. (2013, October 21-24). Report of the expert group meeting on structural and policy constraints in achieving the MDGs for women and girls. Mexico City. Retrieved from http://www.unwomen.org/ /media/Headquarters/Attachments/Sec tions/CSW/58/CSW58-2013-EGM-Report-en.pdf

Vaidyanathan, G. (2014). Sexual and reproductive health services in Tamil Nadu - Progress and way forward. Global Public Health, 10(2), 177-179. doi:10.1080/17441692.2014.986165

World Health Organization. (2005). The right to health. Fact sheet No. 323. Geneva: Author.

World Health Organization. (2011a). Sexual and reproductive health: Core competencies in primary care. Geneva: Author.

World Health Organization. (2011b). Quality of care in the provision of sexual and reproductive health services. Geneva: Author.

World Health Organization. (2014). Ensuring human rights in the provision of contraceptive information and services. Guidance and recommendations. Switzerland: Author. Retrieved from http://apps.who.int/iris/bitstream/10665/102539/1/9789241506748_eng.pdf

Yamin, A. E., \& Boulanger, V. M. (2014). Why global goals and indicators matter: The experience of sexual and reproductive health and rights in the millennium development goals. Journal of Human Development and Capabilities, 15, 218-231. doi:10.1080/19452829.2014.896322 